\title{
Orientador e orientando ideais: similaridades e dissimilaridades na percepção de professores e alunos
}
Advisor and advisee ideals: similarities and dissimilarities in the perception of teachers and students

Orientador y orientado ideales: similitudes y diferencias en la percepción de los profesores $y$ estudiantes

\section{Daiane Pias Machado}

Doutoranda em Contabilidade na Universidade Federal do Paraná

Professora do Instituto de Ciências Econômicas, Administrativas e Contábeis da Universidade Federal do Rio Grande - FURG

Endereço: Rua Dom Pedro I, n॰279, Bairro: Cidade Nova.

CEP: $96211-5600$ - Rio Grande/RS - Brasil

E-mail: daianepiasmachado@yahool.com.br

Telefone: (53) 984044402

\section{Joyce Menezes da Fonseca Tonin}

Doutoranda em Contabilidade na Universidade Federal do Paraná

Professora do Departamento de Ciências Contábeis da Universidade Estadual de Maringá UEM

E-mail: joycemftonin@gmail.com

Telefone: 41999113182

\section{Ademir Clemente}

Pós-doutor em engenharia de transportes pela COPPE/Universidade Federal do Rio de Janeiro e pela University of London

Professor Associado do Departamento de Contabilidade da Universidade Federal do Paraná E-mail: ademir@ufpr.br

Telefone: 4133604413

Artigo recebido em 08/12/2016. Revisado por pares em 18/06/2017. Reformulado em 30/11/2017. Recomendado para publicação em 15/06/2018 por Carlos Eduardo Facin Lavarda (Editor-Chefe). Publicado em 30/06/2018. 


\title{
Resumo
}

O objetivo deste artigo é identificar e comparar as características ideais do orientador e do orientando de dissertações e teses, tanto do ponto de vista de professores quanto de alunos da pós-graduação stricto sensu em contabilidade. Inspirado no modelo bidimensional de Joseph Lowman (2007), foi desenvolvido um instrumento de pesquisa composto por vinte características de orientadores e orientandos, em que os respondentes atribuíam importância a cada atributo em uma escala do tipo likert de 1 a 5 . O estudo possui abordagem quantitativa do problema com a realização dos testes de correlação Tau de Kendall e Spearman. Os dados revelam-se mais consensuais no julgamento do perfil do orientador ideal, em que as seis principais características receberam o mesmo grau de importância por professores e alunos. Sobre os atributos do orientando ideal evidencia-se que as duas primeiras características apresentam o mesmo grau de relevância para professores e alunos. Os testes estatísticos revelam uma similaridade no julgamento de ambos pois não apontam diferenças significativas no grau de importância das características ideais em orientadores e orientandos.

Palavras-chave: Características ideais; Orientador; Orientando; Orientação acadêmica

\begin{abstract}
The purpose of this article is to identify and compare the ideal characteristics of the advisor and advisee of dissertations and theses, both from the point of view of teachers and students of post-graduate stricto sensu in accounting. Inspired by Joseph Lowman's model twodimensional, a research instrument was developed consisting of twenty characteristics of advisor and advisee, in which the respondents assigned importance to each attribute on a scale of 1 to 5. The profile ideal advisor is more consensual, with the first six characteristics received the same importance degree by teachers and students. On the attributes of the ideal advisee it is evident that the first two characteristics present the same degree of relevance for teachers and students. The statistical tests reveal a similarity in the judgment of both because they do not point out significant differences in the importance degree of the ideal characteristics in advisor and advisee.
\end{abstract}

Keywords: Ideal characteristics; Advisor; Advisee; Academic orientation

\section{Resumen}

El propósito de este artículo es identificar y comparar las características ideales de orientador $y$ del orientado de tesis de maestrias y doctorados, tanto de punto de vista de profesores como de alumnos de post-graduación stricto sensu em contabilidad. Inspirado enel modelo bidimensional de Joseph Lowman, fue desarrollado un instrumento de investigación compuesto por veinte características de orientadores y alumnos, en que los investigados atribuy enel valor a cada atributo en una escala de 1 a 5 . Los datos se revelan más consensuales enel juiciodel perfil del orientador ideal, en que las seis principales características reciben elmismo grado de importancia por profesores y alumnos. Sobre los atributos del orientado ideal se destaca que las dos primeras características presentan elmismo grado de importancia relevancia para profesores y alumnos. Las pruebas estadísticas revelan una semejanza enel juicio de ambos, em vista de que no apuntan diferencias significativas en grado de importancia de las caracteristicas ideal esen orientadores y orientados.

Palabras Clave: Características ideales; Orientadores; Orientados; Orientación academica 


\section{Introdução}

Atributos cognitivos e comportamentais que formam o perfil do professor orientador e do orientando delineiam o relacionamento interpessoal desenvolvido durante o processo de orientação acadêmica. Tal relacionamento configura-se em um elemento crítico para a produção de pesquisas de boa qualidade e para o sucesso da pesquisa nas ciências sociais (CASTRO, 1987; HOCKEY,1997).

Cumpre mencionar que o perfil cognitivo e comportamental de cada um desses sujeitos refletirá na qualidade das relações que se desenvolvem no processo de orientação podendo afetar na formação científica dos novos pesquisadores. Nessa perspectiva, a relação orientadororientando insere-se em uma discussão mais ampla, concernente aos relacionamentos humanos, em que é marcada pela mutualidade entre seus dois atores, implicando que o comportamento de um deles reflita no do outro (OLIVEIRA, 2006).

Hinde (1997) afirma que as similaridades ou dissimilaridades pessoais entre aqueles envolvidos em um relacionamento podem gerar efeitos positivos ou negativos na relação. As similaridades das características comportamentais e cognitivas atuam como facilitadoras no processo de comunicação, fortalecendo as crenças positivas sobre o futuro do relacionamento e corroborando com o julgamento consensual nas percepções dos envolvidos. Com isso, as possibilidades de conflitos de opiniões são minimizadas, alcançando-se melhores resultados e tornando os relacionamentos mais satisfatórios.

Por outro lado, as dissimilaridades das características comportamentais atuam na direção oposta, podendo aumentar os conflitos de opiniões e diminuir o grau de satisfação dos relacionamentos. No entanto, as diferenças pessoais também devem ser vistas como canal de intercâmbio de ideias que permitem o desenvolvimento de habilidades e o complemento de conhecimentos. Quando bem administradas, as diferenças podem se transformar em respeito, confiança e compromisso (HINDE,1997).

Armstrong (2004) desenvolveu uma pesquisa em que discute os efeitos do estilo cognitivo e interpessoal sobre a qualidade na orientação da pós-graduação. O autor conclui que o sucesso do trabalho depende dos fatores que predominam a relação orientador e orientando, sejam eles: padrões e habilidade de comunicação, padrões de interatividade, subordinação leal, honestidade, tática de influência, empatia, inteligência, personalidade, respeito, obrigação mútua, dominação e educação.

Rodrigues, Fleith e Alves (2007) realizaram um estudo qualitativo com o objetivo de examinar as interações que ocorrem entre orientador e orientando no transcurso do projeto de dissertação. Os autores identificaram elementos condicionantes que promovem interações de natureza acadêmica: preparo, afinidade acadêmica, interesse, formalidades acadêmicas, rituais acadêmicos e competência na área; e de natureza não acadêmica: afinidade pessoal, disponibilidade de tempo e problemas pessoais.

As diversas características dos orientadores e dos orientandos combinadas com os elementos condicionantes das interações entre eles se convertem em fatores críticos para o sucesso da orientação de dissertações e teses e são responsáveis pela configuração do relacionamento que se formará durante esse processo. É provável que haja convergência na percepção dos orientadores e orientandos quanto a influência dessas características no sucesso do trabalho desenvolvido. No entanto, também podem existir entendimentos conflituosos quanto o grau de intensidade com que cada característica é percebida no sucesso da orientação.

Um distanciamento entre as percepções desses sujeitos sobre as características do orientador ideal e do orientando ideal abre caminho para que as relações interpessoais sejam conflituosas, podendo comprometer o desenvolvimento da dissertação ou tese. Isso contribui para explicação de diversos problemas que surgem no decorrer do curso de mestrado e 
doutorado como: volume significativo de desistências cursos de pós-graduação do Brasil, trocas de orientações no decorrer do curso, além de problemas como a necessidade de prorrogação de prazos para a conclusão da dissertação ou tese.

Diante dessa problematização, pretende-se responder ao seguinte questionamento: Quais características são percebidas por professores e alunos como ideais no perfil do orientador e do orientando de dissertações e teses?

O objetivo do artigo é identificar e comparar a similaridade ou dissimilaridade do perfil ideal do orientador e do orientando na visão desses sujeitos. De forma específica, verifica-se a percepção de professores e alunos do programa de pós-graduação em contabilidade sobre as características que compõem o perfil ideal dos dois sujeitos responsáveis pelo processo de produção acadêmica: orientador e orientando.

Além de se estabelecer em diversos níveis, devido às características pessoais diferenciadas que ambos possuem, as relações singulares, intersubjetivas e complexas que se formam entre eles resultam na produção acadêmica que contribui para a sistematização e consolidação do conhecimento científico (VIANA; VEIGA, 2010; LEITE FILHO; MARTINS, 2006). Por esse motivo, é oportuno estender o escopo de análise da relação orientadororientando ampliando a compreensão de como esses sujeitos percebem a influência das características individuais de cada função no sucesso da orientação acadêmica.

\section{Referencial Teórico}

O relacionamento mútuo entre orientador (professor) e orientando (aluno) determina o processo de construção do conhecimento. Entende-se que esse processo não é uma atividade isolada, e por isto requer a interação entre os sujeitos envolvidos, orientadores e orientandos (TEIXEIRA et al., 2011). Para Grant (2003) a orientação difere de outras formas de ensino e aprendizagem na educação superior, pois não está preocupada apenas com a produção de uma adequada dissertação ou tese, mas também com a transformação do estudante em um pesquisador independente. Na mesma linha, Pearson (1996) considera que o orientador cumpre seu papel quando seu orientando se torna um profissional independente, tanto na pesquisa quanto na docência.

Esta transformação é efetuada mediante a relação de trabalho individualizada entre o orientando e o orientador (GRANT, 2003). Neste contexto, para o sucesso do relacionamento entre eles é necessário que conheçam os seus direitos e deveres, estabelecendo por meio de um relacionamento construtivo o espaço favorável e efetivo para a geração de conhecimento (LEITE FILHO; MARTINS, 2006).

O processo de orientação de uma pesquisa é bilateral e compreende uma complexa interação entre o professor e o estudante. Essa interação exerce um papel significativo que afeta a qualidade do processo de orientação (KAM, 1997). Roesch (1996) ressalta a necessidade de que certas precondições sejam observadas para a realização de uma orientação apropriada. $\mathrm{O}$ orientador deve ter conhecimento na área e também apresentar interesse pelo tema, mas é fundamental que haja certa empatia entre orientador e orientando.

Viana e Veiga (2010) complementam que uma relação orientador-orientando de sucesso exige de ambos: diálogo, dedicação, organização, disciplina, interesse, satisfação, reforçados pelo compromisso e responsabilidade de ambas as partes, destacando a importância da autoavaliação do orientando e do orientador no processo acadêmico.

Além disso, as relações entre eles são dinâmicas e envolvem características pessoais e as subjetividades de cada sujeito que tornarão as interações entre orientador-orientando em vários níveis diferenciados. Essa subjetividade pessoal implica momentos de tensão, conflito, equilíbrio e harmonia, dependendo da sintonia entre os sujeitos envolvidos. Desse modo, a 
orientação acadêmica não se restringe apenas à leitura e a revisão do manuscrito, da dissertação ou da tese, mas envolve outros aspectos interpessoais (VIANA; VEIGA, 2010).

No âmbito das características que influenciam as relações interpessoais no ambiente acadêmico, cumpre destacar um importante trabalho empírico desenvolvido por Joseph Lowman, na década de 1980, que utilizou um grupo de 25 professores de várias disciplinas, em diferentes universidades e faculdades da Carolina do Norte e da Nova Inglaterra, renomados e reconhecidos pelos discentes por serem exemplares. A investigação resultou na construção do Modelo Bidimensional do Ensino Efetivo. Segundo o qual a qualidade do ensino é subdividida em duas dimensões: da qualidade de um professor universitário em criar estímulo intelectual (dimensão I) e da empatia interpessoal (dimensão II) com os estudantes. Ainda de acordo com o autor as habilidades tanto de gerar estímulo como de estabelecer relacionamentos são relativamente autônomas. Desta forma, os professores que dominam as duas habilidades têm amplas probabilidades de obter sucesso no processo de ensino, alcançando uma variedade de metas para os discentes em qualquer ambiente.

A Dimensão I está relacionada à docência em sala de aula enquanto que a Dimensão II está pautada no relacionamento entre professor e aluno dentro e fora de sala de aula. Para Gomes et al. (2009) o ambiente universitário de sala de aula é permeado de fenômenos psicológicos, em que, por exemplo, a motivação dos discentes será diminuída se os estudantes perceberem que não possuem boa aceitação por parte dos seus professores ou mesmo que são controlados de forma impositiva e arbitrária. Todos os alunos são afetados em maior ou menor intensidade por estas emoções, potencializando-se quando forem sujeitados a desafios e avaliações em grupos.

A habilidade para criar estímulo intelectual possui dois componentes: clareza da apresentação do professor - relacionada com o que se apresenta - e seu impacto emocional estimulante sobre os estudantes - que resulta do modo como o material é apresentado. Para que a clareza esteja presente em um ambiente de ensino é necessário que o professor aborde e organize sua matéria se posicionando como leigo no assunto (LOWMAN, 2007). Isso lhe concede a capacidade de explicar um tópico complexo de forma simples. Professores exemplares compartilham essa facilidade de expor claramente o conteúdo e são capazes de explicar ideias e as conexões entre elas de forma que façam sentido para os principiantes no tema. As características do ensino exemplar compreendem o estímulo à reflexão sobre ideias, entender conceitos abstratos, enxergar a sua relevância na sua própria vida, e participar no processo de descoberta (LOWMAN, 2007).

No Quadro 1 apresentam-se os termos associados à dimensão I - Estímulo Intelectual do modelo bidimensional de ensino universitário exemplar identificados na pesquisa desenvolvida por Lowman.

Quadro 1: Dimensão I: Estímulo Intelectual
\begin{tabular}{|l|l|}
\hline \multicolumn{2}{|c|}{ Adjetivos } \\
\hline Entusiástico & Estimulante \\
Culto & Envolvente \\
Inspirador & Preparado \\
Engraçado & Energético \\
Interessante & Divertido \\
Claro & Criativo \\
Organizado & Comunicativo \\
\hline
\end{tabular}

Fonte: adaptado de Lowman, 2007

A Dimensão II do modelo bidimensional do ensino efetivo de Lowman refere-se à consciência que o docente tem desses feitos interpessoais e de sua capacidade em comunicar- 
se com os universitários de modo a aumentar a motivação, o prazer e o aprendizado autônomo. Para que haja o sucesso na Dimensão II, é necessário evitar o despertamento de sentimentos negativos. Por outro lado, é desejável a geração de emoções positivas. Desta forma, a Dimensão II tem como ênfase o bom relacionamento entre professor e aluno.

Em tese, a sala de aula da universidade é um ambiente estritamente intelectual e racional. Porém, na realidade, uma sala de aula também pode ser vista como uma arena interpessoal emocionalmente carregada, em que ocorre um vasto conjunto de fenômenos psicológicos (LOWMAN, 2007). A motivação dos estudantes em trabalhar fora da aula será reduzida se eles não se sentirem apreciados por seus professores ou se forem controlados de modo coercitivo e autoritário. Em geral, os estudantes são vulneráveis a tais emoções que os perturbam, e alguns deles são especialmente sensíveis a elas. Além disso, os estudantes têm um potencial para reagir emocionalmente quando estão sendo desafiados e avaliados em ambientes de grupo (LOWMAN, 2007).

Lowman (2007) considera que os professores também não são imunes ao que acontece em sala de aula; muitos eventos podem interferir em seu prazer de ensinar e diminuir sua motivação para ensinar bem. A maioria deles tem fortes necessidades de realização e de sucesso. Com isso, as salas de aulas universitárias são arenas interpessoais complexas, nas quais uma variedade de reações emocionais pode influir no quanto é aprendido e em como os participantes se sentem sobre isso.

A Dimensão II trata da consciência que o professor tem desses fenômenos interpessoais e de sua habilidade em comunicar-se com os estudantes de modo a aumentar a motivação, o prazer e o aprendizado autônomo. Isso é feito, essencialmente, de dois modos. O primeiro é evitar o estímulo de emoções negativas, principalmente a ansiedade e a raiva excessivas contra o professor. O segundo é promover emoções positivas, tais como o sentimento de que o professor respeita os estudantes como indivíduos e os vê como capazes de um bom desempenho. Esse conjunto de emoções afetam fortemente a motivação do estudante de completar sua tarefa e aprender a matéria (LOWMAN, 2007).

No Quadro 2 apresentam-se os termos associados à Dimensão II - Relacionamento Interpessoal - do modelo bidimensional de ensino universitário exemplar identificados na pesquisa desenvolvida por Lowman.

Quadro 2: Dimensão II: Relacionamento Interpessoal
\begin{tabular}{|l|l|}
\hline \multicolumn{2}{|c|}{ Adjetivos } \\
\hline Interessado & Encorajador \\
Atencioso & Desafiador \\
Disponível & Justo \\
Amigável & Exigente \\
Acessível & Paciente \\
Respeitoso & Motivador \\
Compreensível & Dedicado \\
Simpático & Comprometido \\
Prestativo & \\
\hline
\end{tabular}

Fonte: adaptado de Lowman, 2007

Lowman (2007) considera que os professores exemplares são aqueles que se sobressaem em uma ou ambas dessas duas dimensões do ensino efetivo, e são, pelo menos adequados em ambas dimensões. É possível que esses atributos indicados por Lowman também sejam aplicáveis ao professor na qualidade de orientador, tendo em vista o relacionamento interpessoal entre ele e seu orientando, que por sua vez, é passível de possuir características intelectuais e interpessoais importantes ao sucesso no desenvolvimento de dissertações e teses. 
Este artigo faz esse direcionamento das características intelectuais e interpessoais necessárias ao que seria o modelo de "orientação efetiva", em analogia ao modelo bidimensional do "ensino efetivo" discutido por Lowman (2007).

\section{Procedimentos Metodológicos}

O modelo da pesquisa adotou abordagem de avaliação quantitativa, cujo objetivo principal foi compreender a percepção tanto de professores, quanto de alunos, ambos envolvidos no processo de elaboração de dissertações e teses acerca do perfil ideal do orientador e do orientando.

\subsection{Instrumento}

Para a coleta dos dados foi construído um instrumento de pesquisa composto por três partes. Na primeira parte constam questões de natureza demográfica dos participantes como idade, gênero, qualificador (professor/aluno), dentre outras. A segunda e a terceira parte foram constituídas por 20 características do orientador ideal e do orientando ideal, respectivamente, para as quais deveria ser atribuído, em uma escala de 1 a 5, o grau de importância que cada característica ocupa no perfil do orientador/orientando ideal, na percepção do respondente. A escala do tipo likert foi composta da seguinte forma: 1(indiferente), 2 (pouco importante), 3 (importante), 4 (muito importante) e 5 (crucial/indispensável). $\mathrm{O}$ instrumento da pesquisa foi disponibilizado pela ferramenta do Google Docs. Os dados foram coletados entre os meses de julho e agosto de 2016.

As características que compuseram o instrumento da pesquisa foram embasadas na literatura correlata, principalmente pelo modelo bidimensional de Joseph Lowman (2007) que sugere as características que compõem o perfil do bom professor. Portanto, foram feitas algumas alterações no quadro proposto por Lowman, a fim de que permanecessem somente as características que se aplicassem ao professor na função de orientador, dessa forma, aquelas exclusivas das práticas docentes de "sala de aula" foram excluídas. O instrumento também foi aperfeiçoado com a inclusão de outras características que não estavam presentes no quadro inicial de Lowman, mas que se aplicam à função de orientação. Para tal inclusão, foi solicitado aos alunos da turma de 2015 do doutorado do programa de pós-graduação pesquisado que indicassem livremente palavras que consideram fazer parte do perfil do orientador e do orientando ideal. Esses alunos foram excluídos da amostra. A partir das respostas foram incluídos os adjetivos mais comuns entre eles. Após todos os ajustes o instrumento ficou composto por 20 características para cada uma das funções orientador e orientando, descritas no Quadro 3.

\subsection{Participantes}

O estudo foi desenvolvido junto aos docentes, discentes e egressos do programa de pósgraduação em contabilidade de uma universidade pública, dos cursos de mestrado (2010 a 2016) e doutorado (2014 a 2016), totalizando a população de 157 (144 alunos e 13 professores).

A amostra ficou composta por 133 alunos, tendo em vista que 11 deles não puderam ser contatados devido ao retorno do e-mail lhes enviado, provavelmente não estejam utilizando o $e$-mail cadastrado junto ao PPG. Quanto aos professores, todos foram contatados e fizeram parte da amostra. Dessa forma, foram enviados e-mails a um total de 146 respondentes. Obteve-se um total de 63 respostas dos egressos e atuais alunos e 11 respostas dos professores, totalizando 74 respostas que correspondem a $51 \%$ da população. 


Quadro 3: Características do Perfil do Orientador e Orientado Ideal
\begin{tabular}{|l|l|}
\hline \multicolumn{2}{|c|}{ Características Interpessoais e Intelectuais } \\
\hline \multicolumn{2}{|c|}{ Ambos (Orientador e Orientando) } \\
\hline Acessível, Disponível (AD) & Competente, Eficiente, Preparado (CEP) \\
\hline Amigável, Gentil, Afetuoso (AGA) & Comprometido, Dedicado, Esforçado (CDE) \\
\hline $\begin{array}{l}\text { Bom ouvinte (BO) } \\
\text { Educado, Respeitoso (ER) }\end{array}$ & Criativo (CR) \\
\hline Flexível (FL) & Crítico, Reflexivo (CRE) \\
\hline $\begin{array}{l}\text { Paciente (PA) } \\
\text { Parceiro, Participativo, Prestativo (PPP) }\end{array}$ & Ético, Honesto, Justo (EHJ) \\
\hline Simpático, Atencioso (SA) & Inteligente (IN) \\
\hline \multicolumn{2}{|c|}{ Interessado, Entusiasmado (IEN) } \\
\hline & Responsável, Cuidadoso, Zeloso (RCZ) \\
\hline Desafiador, encorajador, Incentivador, Motivador (DEIM) & \multicolumn{1}{c|}{ Eeterminado, Focado (DF) } \\
\hline Inspirador, Estimulador (IE) & Motivado (MO) \\
\hline Exigente (EX) & Pró-ativo (PRO) \\
\hline Seguro (SE) & Pontual (PON) \\
\hline
\end{tabular}

Fonte: Inspirado em Lowman (2007), com inserções.

\subsection{Procedimentos de Análise dos Dados}

A partir das respostas obtidas foram realizados os testes de correlação Tau de Kendall e Spearman, ambos utilizados para verificar a correlação entre "rankings" e, por serem testes não paramétricos, permitem sua aplicação em variáveis ordinais. O software utilizado para realização dos testes foi o IBM SPSS Statistics, versão 21. Portanto, foram aplicados nos rankings das características mais importantes do orientador e orientando ideal com o objetivo de identificar se existe concordância entre a percepção de alunos e professores quanto as características que compõem esses perfis. Com isso, pretendeu-se verificar se o professores e alunos idealizam os perfis orientador-orientando com as mesmas características. Cumpre mencionar que uma discordância entre essas características possibilita a existência de relações interpessoais conflituosas, podendo comprometer o desenvolvimento da dissertação ou tese.

Adicionalmente, foi realizado o teste Fisher para confirmar se os julgamentos de professores e de alunos que nunca realizaram atividade de orientação são estatisticamente iguais quando comparados aos julgamentos dos alunos que já desempenharam essa atividade.

\section{Análise e Discussão dos Resultados}

\subsection{Perfil dos Respondentes}

Os dados relativos ao perfil dos respondentes estão dispostos na Tabela 1 e revelam uma distribuição equilibrada entre homens e mulheres no que se refere aos alunos que participaram da pesquisa. Quanto aos professores, era de se esperar a maioria masculina, tendo em vista a composição do quadro docente do PPG, que conta com 11 professores e 2 professoras.

Também foi questionado aos participantes se já desenvolveram ou desenvolvem atividade de orientação de pesquisa acadêmica. No caso dos professores, a resposta positiva para essa pergunta é, obviamente, unânime. Mas o objetivo dessa questão é principalmente cotejar junto aos alunos e aos egressos essa prática, tendo em vista que esse fator pode influenciar para a semelhança entre as características de orientador-orientando ideal. Desta forma, $60 \%$ dos alunos e dos egressos desempenham ou já desempenharam a atividade de orientação de pesquisa acadêmica. 
Tabela 1: Perfil dos respondentes

\begin{tabular}{l|c|c|c|c}
\hline Perfil & Aluno (M) & Aluno (D) & Egresso (M) & Professor (M/D) \\
\hline Sexo & & & & \\
Masculino & 13 & 5 & 16 & 2 \\
$\quad$ Feminino & 10 & 4 & 15 & - \\
\hline Idade & & & 13 & 8 \\
Até 30 anos & 13 & 5 & 17 & 3 \\
De 31 a 50 Anos & 9 & 4 & 1 & $\mathbf{1 1}$ \\
Acima de 50 anos & 1 & - & $\mathbf{3 1}$ & \\
\hline Total & $\mathbf{2 3}$ & $\mathbf{9}$ & & \\
\hline
\end{tabular}

Fonte: Dados da pesquisa

\subsection{Características do Orientador Ideal}

O instrumento da pesquisa foi composto por 20 características do orientador ideal, para as quais cada respondente atribuiu um grau de importância que variou de 1 (indiferente) a 5 (crucial/indispensável). A partir do grau de importância atribuído para cada característica, foi calculada a média entre as notas atribuídas por cada respondente, que possibilitou distribuí-las na forma de um ranking, conforme Tabela 2.

Tabela 2: Ranking das Principais Característica do Orientador Ideal

\begin{tabular}{|c|c|c|}
\hline Característica & $\begin{array}{c}\text { Percepção do } \\
\text { Aluno }\end{array}$ & $\begin{array}{l}\text { Percepção do } \\
\text { Professor }\end{array}$ \\
\hline Ético, Honesto e Justo & 1 & 1 \\
\hline Acessível, Disponível & 2 & 2 \\
\hline Competente, Eficiente, Preparado & 3 & 3 \\
\hline Desafiador, encorajador, Incentivador, Motivador & 4 & 4 \\
\hline Educado, Respeitoso & 5 & 5 \\
\hline Comprometido, Dedicado, Esforçado & 6 & 6 \\
\hline Crítico, Reflexivo & 7 & 10 \\
\hline Inspirador, Estimulador & 8 & 9 \\
\hline Interessado, Entusiasmado & 9 & 15 \\
\hline Bom Ouvinte & 10 & 7 \\
\hline Seguro & 11 & 12 \\
\hline Exigente & 12 & 8 \\
\hline Parceiro, Participativo, Prestativo & 13 & 13 \\
\hline Responsável, Cuidadoso, Zeloso & 14 & 11 \\
\hline Inteligente & 15 & 14 \\
\hline Flexível & 16 & 17 \\
\hline Paciente & 17 & 18 \\
\hline Amigável, Gentil, Afetuoso & 18 & 16 \\
\hline Criativo & 19 & 20 \\
\hline Simpático, Atencioso & 20 & 19 \\
\hline
\end{tabular}

Fonte: Dados da pesquisa

As primeiras seis colocações formam um bloco com principais características que um orientador ideal deve apresentar, tendo em vista a similaridade entre as percepções dos alunos e dos professores, revelando um consenso entre eles. Portanto, podem ser consideradas como 
as características fundamentais do orientador ideal. As características que se encontram entre a sétima e a décima quinta posição variam entre si, e demonstram a formação de um novo bloco composto por predicados complementares para a formação do orientador ideal. Adicionalmente, observa-se que os atributos posicionados entre a décima sexta e vigésima posição demonstram ser características secundárias em um orientador ideal.

As principais características indicadas são corroboradas pela pesquisa de Armstrong (2004) ao afirmar que o sucesso do trabalho acadêmico depende dos fatores que predominam na relação orientador e orientando, dentre eles tem-se a comunicação e interatividade, que podem ser percebidas como a acessibilidade ao orientador; sua honestidade; tática de influência, que pode ser capturada pelo sujeito desafiador, encorajador, incentivador e motivador; o respeito e educação, indicados na quinta posição.

Em uma pesquisa realizada na área da medicina, Pinheiro Sá et al. (2015) constatam que a dedicação e responsabilidade dos orientadores correspondem aos elementos mais valorizados por seus orientandos, seguidos da competência prática e teóricas. Elementos aos quais também são atribuídos um alto grau de importância pelos orientandos e orientadores da área contábil.

$\mathrm{Na}$ pesquisa de Rodrigues, Fleith e Alves (2007), alunos e professores indicaram que o interesse por parte do orientador constitui o incidente crítico positivo mais relatado para o sucesso no desenvolvimento de dissertações. A disponibilidade do orientador também foi relatada como importante, na perspectiva do orientando.

Foram realizados os testes de correlação Tau de Kendall e Spearman para verificar o grau de associação entre as respostas dos alunos e professores sobre essas características. Os dados estão dispostos na Tabela 3.

Tabela 3: Associação entre as respostas de professores e alunos

\begin{tabular}{|c|c|c|c|c|}
\hline \multicolumn{5}{|c|}{ Correlações } \\
\hline & & & Aluno & Professor \\
\hline \multirow{6}{*}{ Tau_b de Kendall } & \multirow{3}{*}{ Aluno } & Correlações de coeficiente & 1,000 &, $821^{* *}$ \\
\hline & & Sig. (2 extremidades) & . &, 000 \\
\hline & & $\mathrm{N}$ & 20 & 20 \\
\hline & \multirow{3}{*}{ Professor } & Correlações de coeficiente &, $821^{* *}$ & 1,000 \\
\hline & & Sig. (2 extremidades) &, 000 & \\
\hline & & $\mathrm{N}$ & 20 & 20 \\
\hline \multirow{6}{*}{ Rô de Spearman } & \multirow{3}{*}{ Aluno } & Correlações de coeficiente & 1,000 & ,932** \\
\hline & & Sig. (2 extremidades) & . & 000 \\
\hline & & $\mathrm{N}$ & 20 & 20 \\
\hline & \multirow{3}{*}{ Professor } & Correlações de coeficiente & $932^{* *}$ & 1,000 \\
\hline & & Sig. (2 extremidades) &, 000 & \\
\hline & & $\mathrm{N}$ & 20 & 20 \\
\hline
\end{tabular}

**. A correlação é significativa no nível 0,01 (2 extremidades).

Tanto a estatística de Kendall como de Spearman apresentam um elevado coeficiente de correlação de 0,821 e 0,932 , respectivamente, e ambos significativos ao nível de $1 \%$. A hipótese nula desses testes é de que não existe associação entre as classificações atribuídas pelos professores e alunos quanto as características do orientador ideal. Com isso, observa-se que as características que os orientandos (alunos) consideram desejáveis nos seus orientadores não diferem significativamente $(p$-valor $<0,05)$ das características que os orientadores (professores) consideram desejáveis para si mesmos.

Os mesmos testes foram repetidos comparando as respostas dos professores com as respostas dos alunos que nunca desempenharam a atividade de orientação, com o objetivo de verificar se o fato do aluno nunca ter desenvolvido a atividade de orientação diferencia seu julgamento daquele formado pelos professores que estão acostumados a desempenhar a 
atividade de orientação. É possível que nesse caso, haja menor consenso entre quais qualidades são importantes na figura do orientador ideal. Os resultados revelaram uma singela redução nos coeficientes de correlação de Kendall $(0,811)$ e Spearman $(0,925)$. Portanto, é possível inferir que o julgamento sobre as características do orientador ideal seja menos consensual entre alunos e professores quando se trata de alunos que nunca desempenharam a atividade de orientação.

Entretanto, o resultado do teste Fischer (Tabela 4) não permite rejeitar a hipótese nula de que os valores das correlações de Spearman entre professores e alunos que nunca desempenharam a atividade de orientação sejam iguais. Portanto, independentemente de o aluno ter desenvolvido essa atividade, seu julgamento sobre as características do orientador ideal é igual ao julgamento dos professores a esse respeito.

Tabela 4: Teste Fisher

\begin{tabular}{ll}
\hline Orientador Ideal & Coef. \\
\hline Coeficiente de correlação $\left(\rho_{o}\right)$ & 0,932 \\
Coeficiente de correlação $(\rho)$ & 0,925 \\
\hline 3tab $=1,96$ & \\
3calc $=0,0000$ & \\
3aalc $\leq$ zab: não rejeita $\mathrm{H}_{0}$ & \\
$\mathrm{H}_{0}: \rho=\rho_{o}$ & \\
\hline Fonte: dados da pesquisa &
\end{tabular}

\subsection{Características do Orientando Ideal}

Semelhantemente ao procedimento adotado para a análise da seção anterior, foi calculada a média entre as notas atribuídas por professores e alunos a partir do grau de importância de cada característica do orientando ideal, com isso, tais características foram distribuídas em um ranking, conforme Tabela 5.

Tabela 5: Ranking das Principais Características do Orientando Ideal

\begin{tabular}{|c|c|c|}
\hline Característica & Percepção do Aluno & Percepção do Professor \\
\hline Ético, Honesto e Justo & 1 & 1 \\
\hline Comprometido, Dedicado, Esforçado & 2 & 2 \\
\hline Pontual & 3 & 4 \\
\hline Acessível, Disponível & 4 & 7 \\
\hline Motivado & 5 & 11 \\
\hline Determinado, Focado & 6 & 5 \\
\hline Responsável, Cuidadoso, Zeloso & 7 & 10 \\
\hline Bom Ouvinte & 8 & 12 \\
\hline Educado, Respeitoso & 9 & 8 \\
\hline Interessado, Entusiasmado & 10 & 14 \\
\hline Pró-ativo & 11 & 6 \\
\hline Competente, Eficiente, Preparado & 12 & 3 \\
\hline Crítico, Reflexivo & 13 & 9 \\
\hline Parceiro, Participativo, Prestativo & 14 & 15 \\
\hline Flexível & 15 & 17 \\
\hline Paciente & 16 & 18 \\
\hline Criativo & 17 & 16 \\
\hline Inteligente & 18 & 13 \\
\hline Amigável, Gentil, Afetuoso & 19 & 20 \\
\hline Simpático, Atencioso & 20 & 19 \\
\hline \multicolumn{3}{|l|}{ Fonte: dados da pesquisa } \\
\hline ISSN 2175-8069, UFSC, & $32-47, a b_{1}$ & $\begin{array}{l}\text { Contemporinea de } \\
\text { Ciebhîndade }\end{array}$ \\
\hline
\end{tabular}


Observa-se que é unânime entre professores e alunos que as características fundamentais do orientando ideal correspondem ao comportamento ético, honesto e justo, seguido de comprometimento, dedicação e esforço. Entretanto, nota-se uma diferença significativa entre a caraterística que ocuparia o terceiro lugar no conjunto de qualidades do orientando ideal. $\mathrm{Na}$ percepção dos alunos, a pontualidade é o terceiro elemento mais importante no perfil do orientando, enquanto que na percepção dos professores ser competente, eficiente e preparado seria o terceiro ponto mais importante nas características do orientando ideal. Essa preferência por características técnicas dos orientandos por parte dos orientadores também foi constatada na pesquisa desenvolvida por Leite Filho e Martins (2006).

Outro distanciamento entre as características apontadas pelos respondentes refere-se a característica que deve ocupar o sexto posto no conjunto das qualidades mais importantes. Enquanto os alunos indicam a determinação/foco como sexta característica principal do orientando ideal, os professores indicam que a pró-atividade deve ocupar esse lugar. A pesquisa de Rodrigues, Fleith e Alves (2007) também indica que na percepção dos professores, a iniciativa e autonomia por parte do orientando também é um dos fatores importantes no sucesso da elaboração do trabalho acadêmico.

Embora a segregação em blocos de características não esteja tão nítida quanto nas qualidades do orientador ideal, é possível observar que na análise das características do orientando ideal algumas delas formam um bloco secundário, assim como ocorreu com os orientadores. Isso ocorre com as características apresentadas a partir da décima quarta posição, que constituem as qualidades menos significativas para o perfil do orientando ideal.

Nessa seção também foram realizados o teste de correlação Tau de Kendall e Spearman para verificar o grau de associação entre as respostas dos alunos e professores sobre essas características. Os dados estão dispostos na Tabela 6.

Tabela 6: Associação entre as respostas de professores e alunos

\begin{tabular}{|c|c|c|c|c|}
\hline \multicolumn{5}{|c|}{ Correlações } \\
\hline & & & Aluno & Professor \\
\hline \multirow{6}{*}{ Tau_b de Kendall } & \multirow{3}{*}{ Aluno } & Correlações de coeficiente & 1,000 &, $632^{* *}$ \\
\hline & & Sig. (2 extremidades) & 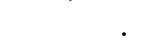 &, 000 \\
\hline & & $\mathrm{N}$ & 20 & 20 \\
\hline & \multirow{3}{*}{ Professor } & Correlações de coeficiente &, $632^{* *}$ & 1,000 \\
\hline & & Sig. (2 extremidades) &, 000 & \\
\hline & & $\mathrm{N}$ & 20 & 20 \\
\hline \multirow{6}{*}{ Rô de Spearman } & \multirow{3}{*}{ Aluno } & Correlações de coeficiente & 1,000 &, $802^{* *}$ \\
\hline & & Sig. (2 extremidades) & . &, 000 \\
\hline & & $\mathrm{N}$ & 20 & 20 \\
\hline & \multirow{3}{*}{ Professor } & Correlações de coeficiente &, $802^{* *}$ & 1,000 \\
\hline & & Sig. (2 extremidades) &, 000 & \\
\hline & & $\mathrm{N}$ & 20 & 20 \\
\hline
\end{tabular}

**. A correlação é significativa no nível 0,01 (2 extremidades).

Ainda que tenha havido maior distanciamento entre algumas características do orientando ideal na percepção de alunos e de professores, tanto a estatística de Kendall como de Spearman apresentam um elevado coeficiente de correlação de 0,632 e 0,802, respectivamente, significativos ao nível de $1 \%$ e rejeitam a hipótese nula de que não existe associação entre as classificações atribuídas por professores e alunos quanto as características do orientando ideal. Com isso, observa-se que as características que os orientadores (professores) consideram desejáveis em seus orientandos não diferem significativamente ( $p$ valor $<0,05$ ) das que os orientandos (alunos) consideram desejáveis para si mesmos.

Semelhante à seção anterior, os mesmos testes foram repetidos comparando as respostas dos professores com as respostas dos alunos que nunca desempenharam a atividade de 
orientação, com o objetivo de verificar se o fato do aluno nunca ter desenvolvido a atividade de orientação diferencia seu julgamento daquele formado pelos professores que estão acostumados a desempenhar a atividade de orientação. É possível que o julgamento de professores e alunos, que nunca desempenharam a tarefa de orientação, sobre as qualidades do orientando ideal sejam menos consensual. Contrariamente, os resultados revelaram um singelo aumento nos coeficientes de correlação de Kendall $(0,653)$ e Spearman $(0,814)$, indicando que, por algum motivo desconhecido, julgamentos sobre as características do orientando ideal entre professores e alunos são mais consensuais quando se trata de alunos que nunca desempenharam a atividade de orientação. Entretanto, o resultado do teste Fischer (Tabela 7) não permite rejeitar a hipótese nula de que os valores das correlações de Spearman entre professores e alunos que nunca desempenharam a atividade de orientação sejam iguais. Portanto, independentemente de o aluno ter desenvolvido essa atividade, seu julgamento sobre as características do orientando ideal é igual ao julgamento dos professores a esse respeito.

\begin{tabular}{ll}
\multicolumn{2}{c}{ Tabela 7: Teste Fisher } \\
\hline Orientador Ideal & Coef. \\
\hline Coeficiente de correlação $\left(\rho_{o}\right)$ & 0,802 \\
Coeficiente de correlação $(\rho)$ & 0,814 \\
\hline 3tab $=1,96$ \\
3calc $=0,0000$ \\
3calc $\leq$ ztab: não rejeita $\mathrm{H}_{0}$ \\
Fonte: dados da pesquisa
\end{tabular}

\subsection{Congruência no julgamento do Professores e Alunos}

Nas Figuras 1 e 2 revela-se graficamente uma congruência maior entre os julgamentos dos professores e dos alunos sobre suas percepções acerca das características do orientador ideal, apresentando sete pontos de intersecção dentre as vinte características estudadas: (Ético, honesto e justo; Acessível e disponível; Competente, eficiente e preparado; Desafiador, encorajador, incentivador e motivador; Educado e respeitoso; Comprometido, dedicado e esforçado; Parceiro, participativo e prestativo).

Figura 1: Orientador Ideal

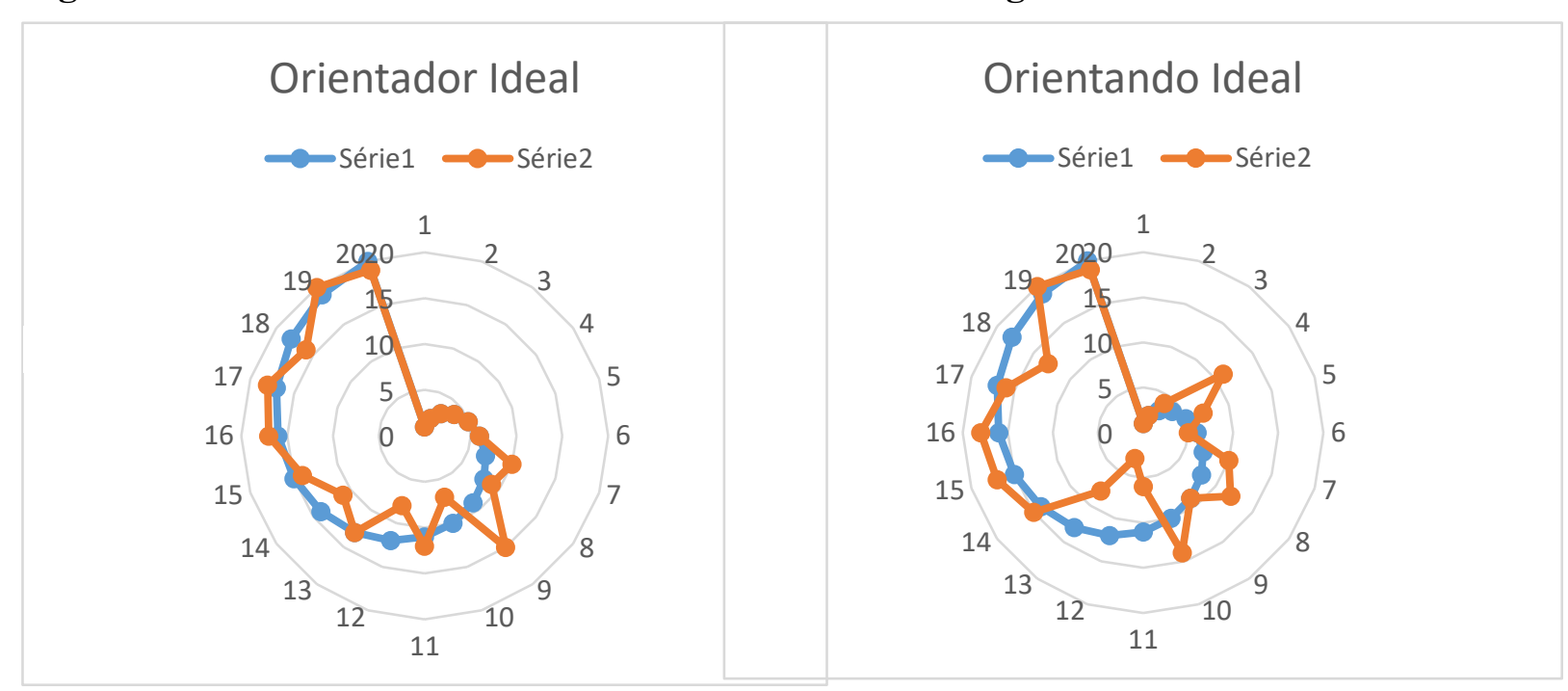

Fonte: dados da pesquisa
Figura 2: Orientando Ideal

Fonte: dados da pesquisa 
No que diz respeito às características do orientando ideal, existe um menor grau de interseção entre os julgamentos dos professores e alunos em torno das características ideais. Os atributos: Ético, honesto e justo; Dedicado e esforçado; Educado e respeitoso apresentaram a mesma posição no ranking dos elementos mais importantes na figura do orientando ideal.

De forma geral, o grau de similaridade entre os julgamentos de professores e alunos é elevado. Ainda que as características de orientadores e orientandos não ocupem exatamente a mesma posição no ranking, foram atribuídos níveis de importância muito parecido entre elas. Esse fato se revela nos gráficos 1 e 2, que denotam um caminho muito próximo entre as distribuições dos níveis de relevância em cada uma delas.

As primeiras seis colocações formam um bloco com principais características que um orientador ideal deve apresentar, tendo em vista a similaridade entre as percepções dos alunos e dos professores, revelando um consenso entre eles. Portanto, podem ser consideradas como as características fundamentais do orientador ideal. As características que se encontram entre a sétima e a décima quinta posição variam entre si, e demonstram a formação de um novo bloco composto por características complementares para a formação do orientador ideal. Adicionalmente, observa-se que as características posicionadas entre a décima sexta e a vigésima posição demonstram ser características secundárias em um orientador ideal.

Cabe ressaltar que não foram identificados estudos empíricos anteriores que houvessem investigado a dissimilaridade ou similaridade entre as características dos sujeitos envolvidos no processo de orientação acadêmica. Em geral, as pesquisas verificam o relacionamento entre orientador e orientando em uma única perspectiva (orientador ou orientando). Viana e Veiga (2010) entrevistaram orientandos e seus respectivos orientadores sobre as contribuições e fragilidades de ambos para o êxito da produção acadêmica, o principal resultado indicou divergências entre as falas dos orientadores e orientandos sobre o sucesso da conclusão da pesquisa.

\section{Considerações Finais}

Este artigo teve como objetivo principal identificar e comparar quais são as características ideais no perfil do orientador e orientando de dissertações e teses percebidas tanto por professores quanto por alunos de um programa de pós-graduação em contabilidade de uma universidade pública. A pesquisa contou com 74 participantes, entre professores, alunos do programa de mestrado e doutorado, bem como egressos do PPG. De forma geral, os resultados não apontam para diferenças estatisticamente significativas quanto à similaridade do julgamento de professores e alunos sobre o grau de importância das características ideais em orientadores e orientandos.

Os dados revelam que as principais características do orientador ideal, na percepção de professores e alunos, em ordem de importância, dizem respeito ao orientador: (1) ético, honesto e justo; (2) acessível e disponível; (3) competente, eficiente e reparado; (4) desafiador, encorajador, incentivador e motivador; (5) educado e respeitoso e (6) comprometido, dedicado e esforçado. Os testes de correlação confirmaram que as características que os orientandos (alunos) consideram desejáveis nos orientadores não diferem significativamente das características que os orientadores (professores) consideram desejáveis para si mesmos, e a similaridade no julgamento entre ambos permanece ainda que o aluno nunca tenha desenvolvido a atividade de orientação.

No tocante as características fundamentais do orientando ideal, ficou evidenciado, tanto na percepção dos alunos quanto na dos professores, que o comportamento ético, honesto e justo, assim como o comprometimento, dedicação e esforço são os atributos mais importantes do aluno responsável pela elaboração de dissertações e teses. Entretanto, algumas dissimilaridades 
no julgamento foram observadas nas demais características de orientandos, a exemplo, na percepção dos alunos, a pontualidade seria o terceiro atributo mais importante em um orientando, enquanto que para os professores essa posição é ocupada pela competência, eficiência e preparação para a tarefa de elaboração da dissertação ou tese.

Acredita-se que os efeitos práticos dessa pesquisa sejam a compreensão e a disseminação das principais características que professores e alunos julgam ser ideais no perfil do orientador e orientando e com isso possam servir como um norteador para o seu desenvolvimento, bem como, para o relacionamento interpessoal durante o desenvolvimento de dissertações e teses, evitando com isso possíveis relações conflituosas que comprometam o desenvolvimento científico, podendo até mesmo desencadear no insucesso da conclusão do trabalho acadêmico. Nesse sentido, este estudo constitui uma primeira visão do que se consideram ser as características ideais no perfil do orientador e do orientando na pósgraduação da área Contábil.

Como pesquisas futuras, sugere-se investigar em que medida a presença ou ausência dos principais atributos cognitivos e comportamentais de orientadores e de orientandos indicados neste trabalho influenciam no sucesso acadêmico do orientando mensurado por sua produção científica.

\section{Referências}

ARMSTRONG, S. J. The impact of supervisors' cognitive styles on the quality of research supervision in management education. British Journal of Educational Psychology, 74(4), 599-616. 2004. doi.org/10.1348/0007099042376436

CASTRO, C. D. M. A prática da pesquisa. 2.ed. McGraw-Hill:1978.

GOMES, M. E. M.; ALBUQUERQUE, L. S.; CARVAlHO, J. R. M. D.; SANTIAGO, J. S.;LUCENA, W. G. L.; RÊGO, T. D. F. Atributos e práticas pedagógicas do professor de contabilidade que possui êxito em sala de aula: estudo da percepção discente em IES públicas. II Encontro De Ensino E Pesquisa Em Administração e Contabilidade-Anais...EnEPQ. Curitiba. 2009.

GRANT, B. Mapping the pleasures and risks of supervision. Discourse, 24(2), 175-190. 2003. doi.org/10.1080/01596300303042

HINDE, R. A. Relationship: a dialectical perspective. Hove. Psycology Press, 1997.

HOCKEY, J. A complex craft: United Kingdom PhD supervision in the sciences. Research in Post-Compulsory Education, 2(1), 45-70. 1997. doi.org/10.1080/13596749700200004

KAM, B. H. Style and quality in research supervision: the supervisor dependency factor. Higher Education, 34(1), 81-103. 1997.

LEITE FILHO, G. A.; MARTINS, G. D. A. Relação orientador-orientando e suas influências na elaboração de teses e dissertações. Revista de Administração de Empresas, 46(SPE), 99109.2006. doi.org/10.1590/S0034-75902006000500008 
LOWMAN, Joseph. Dominando as técnicas de ensino / tradução Harue Ohara Avritscher; consultoria técnica Ilan Avrichir, Marcos Amatucci. - 1. Ed. - 3. Reimp. São Paulo: Atlas, 2007.

OLIVEIRA, A.S. Relação Orientador-Orientando e a Teoria das Relações Interpessoais de Robert Hinde. Dissertação (mestrado em educação), Universidade Católica de Brasília, p.130. 2006.

PEARSON, M. Professionalising Ph. D. education to enhance the quality of the student experience. Higher Education, 32(3), 303-320. 1996.

PINHEIRO SÁ, A.; TEIXEIRA-PINTO, C., VERÍSSIMO, R., VILAS-BOAS, A.; FIRMINOMACHADO, J. Em Busca do Orientador de Formação Ideal. Acta Medica Portuguesa, v. 28, n. 4, 2015. doi.org/10.1007/s12275-013-2393-5

RODRIGUES Jr, J. F.; FLEITH, D. S; ALVES, K. M. B. A dissertação de mestrado: um estudo sobre as interações entre o orientador e o orientando com base em incidentes críticos. Revista Brasileira de Estudos Pedagógicos, 74(177). 2007.

ROESCH, S. M. A. Projetos de estágio do curso de administração. São Paulo: Atlas, 1996.

SEAGRAM, B. C.; GOULD, J.; PYKE, S. W. An investigation of gender and other variables on time to completion of doctoral degrees. Research in higher education, 39(3), 319335.1998 .

TEIXEIRA, E. B.; FROEMMING, L. M.; DREWS, G. A.;ZAMBERLAND, L. Relação orientador-orientadores e seus reflexos na elaboração do trabalho de conclusão de curso (tcc): uma avaliação no curso de administração da Unijuí. 2011. http://repositorio.ufsc.br/xmlui/handle/123456789/25970

VIANA, C. M. Q. Q.; VEIGA, I. P. A. O diálogo acadêmico entre orientadores e orientandos. Educação, 33(3).2010. 